ESJ Natural/Life/Medical Sciences

\title{
An Introduction To Conventional Tensile Testing: Constructionism Approach For Constructivism Learning
}

\author{
Charles Darko \\ Andrij Zadoroshnyj
}

Department of Materials, The University of Manchester, Oxford Road, M13

9PL, Manchester, United Kingdom

Doi:10.19044/esj.2021.v17n3p328

Submitted: 23 November 2020

Accepted: 26 January 2021

Published: 31 January 2021
Copyright 2021 Author(s)

Under Creative Commons BY-NC-ND

4.0 OPEN ACCESS

Cite As:

Darko C. \& Zadoroshnyj A.(2021). An Introduction To Conventional Tensile Testing: Constructionism Approach For Constructivism Learning. European Scientific Journal, ESJ, 17(3), 328.

https://doi.org/10.19044/esj.2021.v17n3p328

\section{Abstract}

Constructivism learning theory recommends the act of allowing students to create knowledge through their experiences. Very often, it is difficult to build such an investigative framework within material science laboratory sessions that assist students in acquiring the knowledge. This paper focuses on the use of constructivism principles that was established by a constructionism process to allow students acquire cognitive knowledge through manual calculation and manipulation of measured data from a tensile testing experiment. Using a conventional tensile laboratory testing, undergraduate material science students succeeded in using their self-acquired skills to determine the toughness of the plastics, the elastic modulus, yield stress and strains, and the ultimate stresses from the measured graphs. The students were also able to describe the deformation mechanisms involved even though the focus was not on the accuracy of the results. This paper reinforces the need to involve constructivism principles in material science teaching that enhances the learner's knowledge acquisition.

Keywords: Constructivism, Constructionism, Tensile Testing, Laboratory Instruction, Plastics 


\section{Introduction}

This work looks into the interpretation of measured tensile test data that gives students the chance to learn and visualize the resulting mechanical properties of the plastics used. The modulus, toughness, yield, and ultimate strengths of the selected plastics were determined. In the constructionism approach, knowledge is shaped and constructed during the building of problem-solving strategies and when the learner actively engages with the construction of those strategies (Ackermann, 2001; Burr, 2015). The moral during the self-directed learning of the learner is always enhanced if the learner engages in the construction of the new knowledge (Talja, et al., 2005; Charmaz, 2008). Currently, as most students study remotely, it is prudent to constructively facilitate their learning and boost their self-efficacies (Abbas \& North, 2018; Feldon et al., 2018). Higher creative self-efficacies were observed to be associated with the lower cognitive load during creativethinking tasks and that suggests that the reinforcement of students' abilities and pre-existing confidence may reduce the perceived difficulties of performing tasks (Redifer et al., 2021). Hence, if the amount of information in the working memory (Lee et al., 2007) are guided and facilitated, positive motivation for learning can be achieved. The approach of this work is to allow or facilitate the learning process of students by allowing them to generate the meaning of the data without the use of computational methods.

Moreover, constructivism learning theory recommends the act of allowing students to create knowledge through their experiences (Sjøberg, 2007; Bada \& Olusegun, 2015). In addition, it helps them to actively engage with the task without receiving it passively from the lecturer (Liu \& Chen, 2010). The knowledge must constantly be reconstructed via personal experiences through the development of students' cognitive tools (Ackermann, 2001). However, constructivist principles in both conventional campus-based and distance education practices are minimal at our higher education institutions and that may be linked to the difficulty in the implementation (Tenenbaum et al., 2001).

\section{Purpose of this Study}

Major issues emerging from the literature review have recognized the pedagogical needs for laboratory teachers to combine theory with practice and provide deep learning laboratory experiences for students (Prabha, 2016). This work seeks to implement constructivist principles that will allow students (i.e., on-campus and off-campus) to explore the evaluation processes of a conventional tensile laboratory testing data (Davis, 2004). The idea is to build a framework within the material science program (i.e., constructionism principle) that will assist students to investigate, build, and acquire knowledge. The approach will allow manual calculations and interpretations of the 
measured data to develop students' cognitive skills and encourage knowledge reinforcement.

\section{Tensile Testing of Plastics}

Mechanical properties of plastics are essential parameters used by material engineers in their material selections (Meyers \& Chawla 2008; Dowling, 2012). Tensile testing is one of the important traditional material testing technique that evaluates the strength and toughness of polymer materials (Davis, 2004). The tensile testing is simply placing a specimen under tension until failure. Tensile experiments have been used to train students (McCormick, 1975; Gilmer \& Williams, 1996) and clear guidance on the procedure for testing of polymers have been given (Gilmer \& Williams, 1996).

Plastics such as polyethylene ( $P E)$, low-density polyethylene ( $L D P E)$, high-density polyethylene (HDPE), and polystyrene (PS) were carefully selected due to their unique properties (Scheirs \& Priddy, 2003). The HDPE is more crystalline than $L D P E$ and the PS is completely glassy. The structure of the plastics affects their transition temperatures and this has a significant influence on their applications (Boyer, 1963). The primary transition temperatures are glassy transition $\left(T_{\mathrm{g}}\right)$ and the melting transition $\left(T_{\mathrm{m}}\right)$. A plastic that exists below its $T_{\mathrm{g}}$ and $T_{\mathrm{m}}$ is rigid. For instance, an amorphous PS has a $T_{\mathrm{g}}$ of around $105^{\circ} \mathrm{C}$; hence, it exists as a rigid plastic at room temperature (Rieger, 1996). Plastics that exist above their $T_{\mathrm{g}}$ 's but below $T_{\mathrm{m}}$ 's are generally soft or rubbery at room temperatures. In our case, both $L D P E$ and HDPE exist above their $T_{\mathrm{g}}$ 's (i.e., between -78 to $-110^{\circ} \mathrm{C}$ ) (Stehling \& Mandelkern, 1970; Gaur \& Wunderlich, 1980; Yang et al., 2016) but below their $T_{\mathrm{m}}$ 's (i.e., $115^{\circ} \mathrm{C}$ ) (Weeks, 1963).

However, most of the unique physical properties influence the mechanical deformation behaviours when measured by a static tensile test (Davis, 2004). Soft plastics are not stiff but they have long plastic deformation, while rigid plastics have distinct elastic properties as depicted in Figure 1. The elastic regime is the initial linear part of the stress-strain curve that describes the plastics ability to resist any permanent change under load (Askeland \& Phulé, 2006).

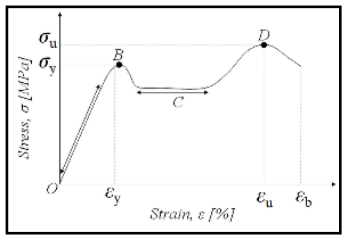

Figure 1. Generalized stress-strain curve. The section between $O$ and $B$ is the elastic region while point $B$ and $D$ are the yield and breaking points, respectively. Part $C$ represents the plastic deformation region. 
In uniaxial tension, most plastics exhibits yielding at the end of the elastic limit before plastic deformation begins (Young \& Lovell, 2011a). Most soft and amorphous plastics yield as a result of necking and emerge with different draw ratios (i.e., the length of a fully necked specimen divided by the original length). Nevertheless, the yielding in semi-crystalline plastics are associated with the uncoiling of the crystalline chains (Young \& Lovell, 2011a). Glassy and brittle plastics yield as a result of shear band formation and crazing (i.e., a localized form of plastic deformation that creates microcracks) (Haward et al., 1971; Argon \& Bessonov, 1977).

\section{Experimental Method}

The main goal was to perform a normal tensile testing experiment and then allow students to construct the meaning of the data themselves by performing manual data analysis. They were allowed to compare their results with the literature data even though the focus was not on the accuracy of the results.

To facilitate the constructionism process, the laboratory experiments were performed by about hundred and forty (140) students from the undergraduate material science program for two years and each laboratory session involves ten (10) student-groups per semester. For ethical reasons, consents from ten groups were sought and their results were used in this study. Their measured data can be seen in section 7 under the appendix. All samples were tested at room temperature. Dumbbell specimens bought from Modulus and Matrix company polymers, United Kingdom, were prepared by injection moulding. Thus, they are of different colours to allow visualization of the changes in the physical appearances during the deformation. The characteristics of the PE, LDPE, HDPE, and the PS plastics are shown under the appendix. Under the appendix, the sample specimen geometry and test routine have also been discussed.

An Instron tensile testing machine (Instron, 2020) was used. A forceextension (i.e., in $\mathrm{mm}$ and $\mathrm{kN}$ ) curves were recorded electronically by an attached computer using a clamped length of $120 \mathrm{~mm}$ (see specimen dimensions in appendix). Cross-head speed for PS and HIPS (high impact polystyrene) was selected to be $5 \mathrm{~mm} / \mathrm{min}$ while $25 \mathrm{~mm} / \mathrm{min}$ was chosen for LDPE and HDPE specimens because Polyethylene elongates more than the Polystyrene. The speeds were selected to allow complete visualization of the deformation processes within the two-hour session.

\section{Constructivism Data Evaluation Processes}

To guide the construction of knowledge (Talja, et al., 2005; Charmaz, 2008), the following guidelines were given to lower the cognitive load and 
reduce the perceived difficulty of performing data analysis (Redifer et al., 2021).

In Figure 1, the important parameters in stress-strain curves are the elastic modulus $(E)$, yield stress $(\sigma \mathrm{y}) \&$ strain $\left(\varepsilon_{\mathrm{y}}\right)$, ultimate stress $\left(\sigma_{\mathrm{u}}\right) \&$ strain $\left(\varepsilon_{\mathrm{u}}\right)$, and elongation at break $\left(\varepsilon_{\mathrm{b}},\right)$. The $\sigma_{\mathrm{y}}, \varepsilon_{\mathrm{y}}, \sigma_{\mathrm{u}}, \varepsilon_{\mathrm{u}}$, and $\varepsilon_{\mathrm{b}}$ were obtained directly from the measured graph but $\mathrm{E}$ was determined from the slope at the linear part of the graph (Figure 1) and was related to the equation below.

$$
E=\frac{\text { Change in stress }(M P a)}{\text { Change in Strain (unitless) }}=\frac{\Delta \sigma}{\Delta \varepsilon} \times 100(M P a)
$$

The strain was expressed as a percentage. Hence, the equation was multiplied by 100 .

The tensile toughness $\left(U_{\mathrm{T}}\right)$ was evaluated using the area under the stress-strain curves (MechaniCalc, 2020). The tensile toughness is the total deformation energy per unit volume that the material can withstand before failure (NDT Resource centre, 2020). Therefore, this is different from the fracture toughness measured by an impact load (Seidler \& Grellmann, 1995). The toughnesses of the plastics were determined manually using the Trapezium rule (Joyce, 1971; Yeh, 2002). This is an approximation method that represents the definite integral of the region under the graph. The area under the curves was divided into a regular number of partition spacing $(n)$ and each spacing $(\Delta x)$ had values defined by the lower and upper limits of the curves, $a$ and $b$, shown in equation 2 below.

$$
\Delta x=\frac{b-a}{n}
$$

For a graph having a function, $\mathrm{y}=f(x)$, with a partition spacing $(\Delta x)$, the Trapezium rule is given by (Maths24, 2020);

$$
\text { Area }=\frac{\Delta x}{2}\left[f\left(x_{1}\right)+f\left(x_{n}\right)+2\left(f\left(x_{2}\right)+f\left(x_{3}\right)+f\left(x_{4}\right)+\ldots \ldots f\left(x_{n-1}\right)\right)\right]
$$

Where $f\left(x_{1}\right), f\left(x_{2}\right), f\left(x_{3}\right) \ldots \ldots f\left(x_{\mathrm{n}}\right)$ are the functions of each partition from 1, 2, 3 to $n$ number of partitions. This can also be written as;

$$
\text { Area }=\frac{\Delta x}{2}\left[y_{1}+y_{n}+2\left(y_{2}+y_{3}+y_{4}+\ldots \ldots . y_{n}\right)\right]
$$

The unit for the toughness is $\mathrm{MPa}$ (or $\mathrm{kJ} / \mathrm{m}^{3}$ ). 
Plastics that can undergo significant plastic deformation before the break are tough and are mostly evaluated by the essential work of fracture (Karger-Kocsis, 1996; Ching et al., 2000). Nonetheless, in the uniaxial tensile testing, it is analyzed by calculating the area under the stress-strain curve (Brostow, 2015). Brittle and glass polymers such as PS can be toughened by adding a small amount of polybutadiene rubber chemically (Bucknall, 1977) or through blending (Fowler, 1988). The rubber particles in the toughened PS controls the crazing or shear yielding during deformation (Gilbert \& Donald, 1986; Young \& Lovell, 2011b).

\section{Results}

The following are the summary from the students' reports. It is worthy to mention that the focus was on the practical aspects that allows knowledge acquisition during the data evaluation processes without relying too much on the data accuracy.

\section{Observation and Characterization of LDPE Measurement}

At the initial stages, the specimens elongated steadily and extended without necking nor crazing. Consequently, no colour change was observed on the specimen surfaces. Before the failure, voids that looked like two dimples appeared on the specimen surfaces within the gauge lengths (Figure $2 a$ ). Figure $2 b$ provided evidence that there were no significant yielding before the commencement of the deformation (i.e., the plastic deformation). An elastic modulus of $0.19 \mathrm{GPa}$, the yield stress of $6.80 \mathrm{MPa}$, and a tensile toughness of $6.90 \mathrm{MPa}$ (see Table 1) were evaluated from the graph.

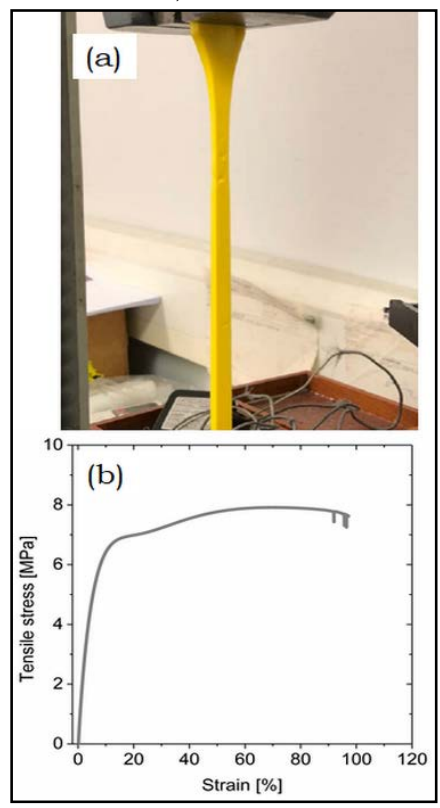


Figure 2. $L D P E$ tensile test measurement. (a) Experimental observation during the test. The image shows the appearance or formation of surface voids in the middle of the specimen during the testing. $(b)$ The corresponding stress-strain curve measured during the test.

Yielding in amorphous materials may be linked to the stretching, rotation, sliding, and disentanglement of the chains during loading deformation (Mouritz, 2012). The absence of a distinct yielding may suggest that the chains were less entangled and were able to elongate from their relaxed state.

Hence, the chain molecules elongated to a large extent and oriented anisotropically along the load direction before failure (Hennig, 1967). This is evident in the experimental observations such that there were no necking of the specimen and the only rearrangement within the chains might have caused the surface dimples during the deformation.

\section{Observation and Characterization of HDPE Measurement}

Initially, the specimens extended slowly but was necked within the gauge lengths after about $240 \mathrm{~mm}$ extensions (Figure $3 a$ ). The cold drawings or the neckings were characterized by narrow stem regions and moderate colour changes within the gauge length as shown in Figure $3 a$. The extension during the necking continued until a draw ratio of about 3.5 was reached after which most specimens broke. After the fracture, elongated fibrous structures were formed (see section 11 in appendix). In Figure 3b, there were distinct yielding peaks before the large drop in stresses (i.e., roughly half of the yield stresses) occurred due to the necking processes. For this semi-crystalline polyethylene, an elastic modulus of 1.12 GPa, yield stress of $19.80 \mathrm{MPa}$, and a tensile toughness of $20.50 \mathrm{MPa}$ (see Table 1 ) were obtained.

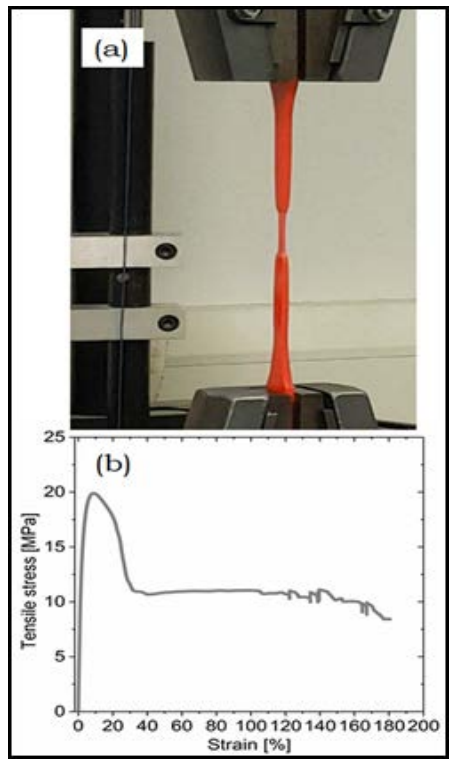


Figure 3. HDPE tensile test measurement. (a) Experimental observation during the test. Necking of the specimen began after $240 \mathrm{~mm}$ extension and the stem of the sample became thinner during the cold drawing. $(b)$ The corresponding stress-strain curve measured during the test.

The distinct yielding peaks were due to the uncoiling of the folded crystalline chains (Wada, 1971). It is an accepted truth that during the early start of necking, the crystalline chains deform homogeneously and the crystalline regions deform by combinations of slips, twinnings, etc. (GaucherMiri \& Séguéla, 1997). It was noted that stacked crystals, with folded molecules, deform by slip and twinning until the crystals rupture and chains were pulled out (Young \& Lovell, 2011a). Under sufficiently high strains, the crystal chains became aligned parallel to the stretched directions and fibrillar structures formed before fracture.

\section{Observation and Characterization of PS Measurement}

For these amorphous and glassy specimens, the extensions lasted for some few minutes and white lines developed nearly at $2.21 \mathrm{~mm}$ extensions (Figure 4a). The white lines, perpendicular to the loading direction, appeared to be clouded white lines and the specimen broke soon after that without experiencing any cold drawing or necking. In Figure $4 b$, the measured stressstrain curve confirmed the breaking of the specimens after short strain periods (i.e., $~ 1.5 \%$ ). An evaluation of the stress-strain curve revealed an elastic modulus of 2.60 GPa, the yield stress of $37.20 \mathrm{MPa}$, and a tensile toughness of $0.30 \mathrm{MPa}$ (see Table 1 ).

In uniaxial tension, the main reason for the whitening effects in PS specimens is the formation of small cracks that causes the scattering of light because of the different sizes of cracks and the void space created. The formation of those small cracks and voids are termed crazings (Kambour, 1973; Argon \& Salama, 1977). The crazing causes the materials to undergo significant increases in volumes that emerge as small splits or cracks oriented perpendicular to the tensile axis (Kinloch, 2013). In the crazing zones, fractured polymer fibres with small voids like cracks existed and lead to eventual failure. 


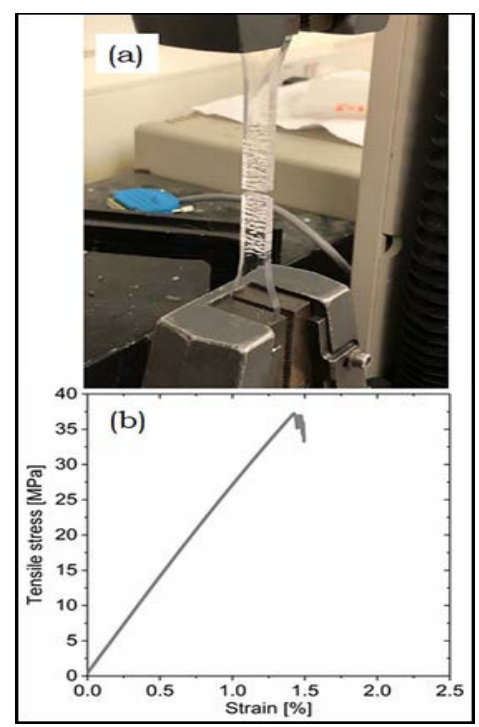

Figure 4. PS tensile test measurement. (a) Experimental observation during the test. Crazes caused strong whitening of the specimens within the gauge length before fracture. $(b)$ The corresponding stress-strain curve measured during the test.

\section{Observation and Characterization of HIPS Measurement}

Immediately after the commencement of the test, the deep blue specimens (Figure 5a) turned into distinct pale-blue, with associated white lines, at the vicinity of the gauge ends. Later on, the distinct pale-blue were visible on the entire gauge lengths. At the breaking point, the straight gauge lengths of the specimens curled and small to large horizontal cracks were observed. The corresponding stress-strain curve revealed a narrow yielding peak having a yield stress of about $19 \mathrm{MPa}$ and an appreciable plastic deformation before the break (Figure $5 b$ ). An elastic modulus of $1.90 \mathrm{GPa}$, the yield stress of $18.60 \mathrm{MPa}$, and a tensile toughness of $3.30 \mathrm{MPa}$ were calculated from the stress-strain curve (see Table 1).

For these toughened polystyrene specimens, the inclusion of the rubbery phase caused the materials to undergo yieldings and plastically deformations before fracturing (Donald \& Kramer, 1982a). Under such composite structures, the plastic deformations are often accompanied by stress-whitenings and the necked regions become white in appearance during deformations (Bucknall \& Smith, 1965). Thus, these are due to the formation of a large number of crazes around the rubber particles within the material (Donald \& Kramer, 1982b). 


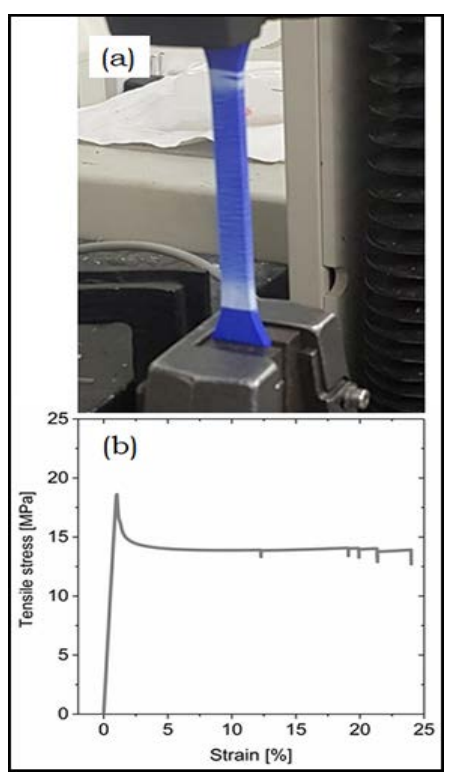

Figure 5. HIPS tensile test measurement. (a) Experimental observation during the test. Horizontal narrow cracks formed distinct whitening effects throughout the gauge length. $(b)$ The measured stress-strain curve shows a yielding peak and the plastic deformation region.

\section{Constructivism Data Evaluation}

At the end of the experiment, the students were tasked to manually analyze the data after plotting the stress-strain graphs by using the guidance discussed under constructivism data evaluation processes section above. To allow the establishment of the constructivism learning principles, which is difficult to implement (Tenenbaum et al., 2001), students were instructed to perform the evaluations on their own and share the experiences during the data analysis. For the toughness determination, they were supposed to vary the partition spacing $(\Delta \mathrm{x})$ and discuss the resulting data. The following were the summary of what the student reported.

\section{Determination of Elastic Modulus (E)}

From equation (1), the $E$ was calculated using the slope of the linear region on the stress-strain curves. For example, from Figure 6, the slope of the $L P D E$ elastic region was analyzed as follows. The slope was evaluated as:

$$
\Delta \sigma / \Delta \varepsilon=1.94
$$




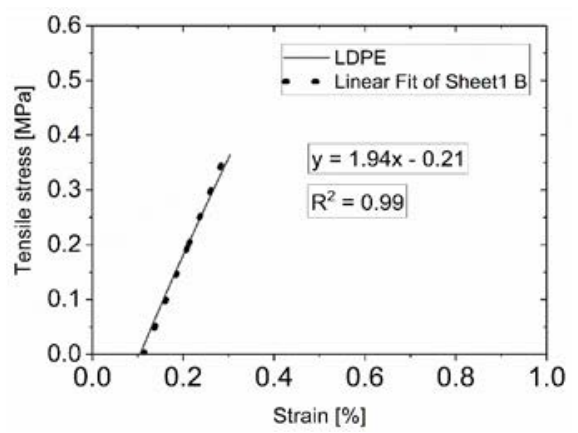

Figure 6. $L D P E$ slope determination at the linear region. The average stress-strain curve from the ten experimental measurements was used.

Therefore,

$$
\begin{aligned}
& E=1.94 \times 100(M P a) \\
& E=194(M P a)=0.194 G P a
\end{aligned}
$$

Hence, the E value for LDPE was 0.19 GPa. Other E values were evaluated using the same procedure (see section 9 in appendix). The $E$ values for HDPE, PS and HIPS were obtained to be 1.12, 2.6 and $1.9 \mathrm{GPa}$, respectively.

\section{Estimation of Tensile Toughness $\left(U_{T}\right)$}

Using equation 4, the area under the LPDE curve (Figure 7) was estimated with a $\Delta x$ of 0.097 since $n$ was selected to be 10 while $a=0$ and $b$ $=0.97$ (i.e., value as decimal). Starting from 0 and a $\Delta x$ of $0.097, x$ values were generated to be $x=0,0.097,0.194,0.291,0.388,0.485,0.582,0.679,0.776$, 0.873 , and 0.97 .

Figure 7 shows that the corresponding $\mathrm{y}$ values of $\mathrm{x}$ were picked from the graph to be $y=0,6.38,6.98,7.20,7.51,7.74,7.87,7.91,7.90,7,84$, and 7.63. Using equation 4, the area under the curve becomes;

$$
\text { Area }=\frac{\Delta x}{2}\left[y_{0}+2 y_{1}+2 y_{2}+2 y_{3}+2 y_{4}+2 y_{5}+2 y_{6}+2 y_{7}+2 y_{8}+2 y_{9}+y_{n}\right]
$$

Inserting the $y$ values gives;

$$
\begin{aligned}
\text { Area }= & \frac{0.097}{2}[0+2(6.38)+2(6.98)+2(7.20)+2(7.51) \\
& +2(7.74)+2(7.87)+2(7.91)+2(7.90)+2(7.84)
\end{aligned}
$$




$$
\begin{aligned}
\text { Area } & =\frac{0.097}{2}[142.29] \\
\text { Area } & =6.9 \mathrm{MPa}
\end{aligned}
$$

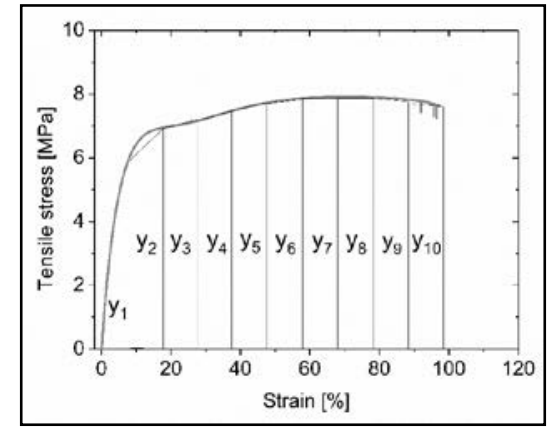

Figure 7. Determination of toughness under the $L P D E$ tensile curve.

Hence, the toughness of LDPE was calculated to be 20.5 MPa. Using a similar analytical procedure, the $\left(U_{\mathrm{T}}\right)$ values for HDPE, PS, and HIPS were estimated to be 20.5, 0.3, and 3.3 MPa (see section 10 in appendix).

\section{Summary of Measured Results and Comparisons}

The following table summarizes the results obtained from the students. As shown below, the students compared the deformation behaviour between LDPE and HDPE as well as PS and HIPS. Finally, in their discussions, they compared their measured data with the literature (see section 14 in appendix).

\section{Comparison between LDPE and HDPE}

The HDPE is much stiffer and tougher than the LDPE because it had a higher yield and ultimate stress as well as greater tensile toughness. A material that has a higher degree of crystallinity would theoretically have a higher Elastic Modulus as the crystalline regions increase the sample stiffness by restricting the molecular motion (Humbert et al., 2011). Hence, HDPE is stiffer $(E=1.12 \mathrm{GPa})$ than $L D P E(E=0.19 \mathrm{GPa})$ as shown in Table 1. The much higher yield stress of HDPE is as the result of the reinforcement ushered by the crystalline regions that prevented the molecular chains from yielding too easily (Wada, 1971). It is accepted that the crystalline chains must uncoil and stretch before breaking. The necking (Gaucher-Miri \& Séguéla, 1997) of the HDPE significantly increased the area under the curve and that promoted the increase in the toughness value. 


\section{Comparison between PS and HIPS}

The inclusion of the rubbery phases within the PS domain allowed the brittle PS (Figure 4b) plastic to yield and deform plastically (Figure $5 b$ ). Naturally, the microstructure of $P S$ is such that the chains are frozen in high energy conformations, since the plastic is below its $T_{\mathrm{g}}$ (i.e. $\sim 105^{\circ} \mathrm{C}$ ) (Rieger, 1996). Therefore, this results in promoting a restrictive movement of chains while raising the energy needed to break the material. Furthermore, the rubber particles within the HIPS lowered the elastic modulus and the yield stress (see Table 1).

Interestingly, the presence of the rubber particles in HIPS controls the crazing mechanisms within the PS domain. These led to stress concentrations at the equators of the particles during the mechanical deformation similar to the stress concentration found around holes and notches (Young \& Lovell, 2011b). The stress concentrations may lead to shear yielding or crazing around every rubber particle and hence throughout the large volume of the material rather than just at the crack tip. Hence, the polymer adsorbs a large amount of energy during the deformation.

Table 1. Mechanical properties obtained after the experiment

\begin{tabular}{|c|c|c|c|c|c|c|}
\hline $\begin{array}{c}\text { Parameter } \\
\mathrm{s}\end{array}$ & $\begin{array}{c}\text { Tensile } \\
\text { modulus, } \\
E(\mathrm{GPa})\end{array}$ & $\begin{array}{c}\text { Yield } \\
\text { stress, } \\
\sigma_{\mathrm{y}}(\mathrm{MPa})\end{array}$ & $\begin{array}{c}\text { Yield } \\
\text { strain, } \\
\varepsilon_{\mathrm{y}}(\%)\end{array}$ & $\begin{array}{c}\text { Ultimate } \\
\text { stress, } \\
\sigma_{\mathrm{u}}(\mathrm{MPa})\end{array}$ & $\begin{array}{c}\text { Ultimate } \\
\text { strain, } \\
\varepsilon_{\mathrm{u}}(\%)\end{array}$ & $\begin{array}{c}\text { Tensile } \\
\text { Toughn } \\
\text { ess } U_{\mathrm{T}} \\
(\mathrm{MPa})\end{array}$ \\
\hline LDPE & 0.19 & 6.80 & 14.00 & 7.90 & 69.90 & 6.90 \\
\hline$H D P E$ & 1.12 & 19.80 & 10.50 & 19.80 & 10.50 & 20.50 \\
\hline$P S$ & 2.60 & 37.20 & 1.40 & 37.20 & 1.40 & 0.30 \\
\hline HIPS & 1.90 & 18.60 & 1.03 & 18.60 & 1.03 & 3.30 \\
\hline
\end{tabular}

\section{Constructed Knowledge}

The approach of employing the constructivism principle in the data evaluation process enhanced the students' cognitive learning, and they demonstrated a clear understanding of the topic in their reports. During oral discussions, students gave positive feedback about the process and pointed out that they tried so many ways to get the partition spacing as accurate as possible. After many attempts, they developed the concepts and were able to get the work done. Thus, they built skills through active mental work and not by receiving it passively from the instructor (Sjøberg, 2007). The students also observed that even though it was not easy to find the slopes of the elastic linear regions, they learned from the experiences. They would not have acquired those experiences if they employ a computational analytical methods. Their difficulties stem from the determination of the real linear regions. The acquired skills enabled them to overcome other difficulties, thereby improving their confidence. This is in line with the constructivist teaching approach that 
instructs instructors to activate the cognitive thinking process by setting explorable and supportive tasks in their sessions (Ackermann, 2001).

The outcome of this study is comparable to previous studies (Kim et al., 1999; Kim et al., 1999; Neo \& Neo, 2009) where constructivism principles were used to improve students' learning. First of all, the constructivism principle was used to increase students' reading comprehension. This indicated that the implemented strategies increased the students' reading comprehension effectively compared to the conventional method (Yussof, 2012). Secondly, a new general science curriculum which reflects a constructivist view was introduced into the curriculum and that promoted a positive classroom learning environment (Kim et al., 1999). Finally, students' perceptions while working on a multimedia project in a constructivist-based learning environment were investigated (Neo \& Neo, 2009). Also, it was reported that the students showed positive attitudes towards the project in their learning, motivation, understanding, skills, and their teamwork abilities.

\section{Conclusion}

This paper demonstrates the act of allowing students to acquire cognitive knowledge through the use of constructivism principles built up by constructionism process. Students were tasked to perform manual data analysis after a tensile testing laboratory session and that allowed them to construct analytical skills. The students were able to apply the knowledge acquired in their work to solve other problems. They succeeded in learning simple ways of approximating the toughness of the plastics using the Trapezium rule in the determination of the area under the stress-strain curves, thus improving their constructive learning processes. The students also managed to evaluate the elastic modulus, yield stress and strains, and the ultimate stresses from the measured graphs. Furthermore, the students managed to describe the deformation mechanisms behind each selected plastic. Therefore, this paper reinforces the need to involve the constructivism principles in our teaching that will enhance the learner's knowledge construction.

\section{Acknowledgements}

The authors wish to thank all undergraduate students who were involved in the laboratory sessions.

\section{References:}

1.Abbas, Z. A., \& North, J. S. (2018). Good-vs. poor-trial feedback in motor learning: The role of self-efficacy and intrinsic motivation 
across levels of task difficulty. Learning and instruction, 55, 105-112. https://doi.org/10.1016/j.learninstruc.2017.09.009.

2.Ackermann, E. (2001). Piaget's constructivism, Papert's constructionism: What's the difference. Future of learning group publication, 5(3), 438.

3.Burr, V. (2015). Social constructionism. Routledge. https://doi.org/10.4324/9781315715421

4.Argon, A. S., \& Bessonov, M. I. (1977). Plastic flow in glassy polymers. Polymer Engineering \& Science, 17(3), 174-182. https://doi:10.1002/pen.760170306.

5.Argon, A. S., \& Salama, M. M. (1977). Growth of crazes in glassy polymers. Philosophical Magazine, 36(5), 1217-1234. https://doi:10.1080/14786437708239790.

6.Askeland, D. R. \& Phulé, P. P. (2006). The science and engineering of materials. 5th ed.: Cengage Learning.

7.Bada, S.O., \& Olusegun, S. (2015). Constructivism learning theory: A paradigm for teaching and learning. Journal of Research \& Method in Education, 5(6), 66-70. https://doi:10.9790/7388-05616670.

8.Boyer, R. F. (1963). The relation of transition temperatures to chemical structure in high polymers. Rubber Chemistry and Technology, 36(5), 1303-1421. https://doi:10.5254/1.3539649.

9.Brostow, W., Lobland, H. E. H., \& Khoja, S. (2015). Brittleness and toughness of polymers and other materials. Materials Letters, 159, 478-480. https://doi:10.1016/j.matlet.2015.07.047.

10. Bucknall, C. B. (1977). Toughened plastics. Applied Science Publishers, 182-211. London. https://doi.org/10.1007/978-94-0175349-4_7.

11. Bucknall, C. B., \& Smith, R. R. (1965). Stress-whitening in highimpact polystyrenes. Polymer, 6(8), 437-446. https://doi:10.1016/0032-3861(65)90028-5.

12. Charmaz, K. (2008). Constructionism and the grounded theory method. Handbook of constructionist research, 1, 397-412.

13. Ching, E. C., Poon, W. K., Li, R. K., \& Mai, Y. W. (2000). Effect of strain rate on the fracture toughness of some ductile polymers using the essential work of fracture (EWF) approach. Polymer Engineering \& Science, 40(12), 2558-2568. https://doi:10.1002/pen.11386.

14. Davis, J. R. (2004). Tensile testing, $2^{\text {nd }} E d$.; ASM international.

15. Donald, A. M., \& Kramer, E. J. (1982). Internal structure of rubber particles and craze break-down in high-impact polystyrene (HIPS). Journal of Materials Science, 17(8), 2351-2358. https://doi:10.1007/BF00543744. 
16. Donald, A. M., \& Kramer, E. J. (1982). Craze initiation and growth in high-impact polystyrene. Journal of Applied Polymer Science, 27(10), 3729-3741. https://doi:10.1002/app.1982.070271009.

17. Dowling, N. E. (2012). Mechanical behavior of materials: engineering methods for deformation, fracture, and fatigue. 4th ed. Pearson.

18. Feldon, D. F., Franco, J., Chao, J., Peugh, J., \& Maahs-Fladung, C. (2018). Self-efficacy change associated with a cognitive load-based intervention in an undergraduate biology course. Learning and Instruction, 56 , 64-72. https://doi.org/10.1016/j.learninstruc.2018.04.007.

19. Fowler, M. W., \& Baker, W. E. (1988). Rubber toughening of polystyrene through reactive blending. Polymer Engineering \& Science, 28(21), 1427-1433. https://doi:10.1002/pen.760282112.

20. Gaucher-Miri, V., \& Séguéla, R. (1997). Tensile yield of polyethylene and related copolymers: mechanical and structural evidences of two thermally activated processes. Macromolecules, 30(4), 1158-1167. https://doi:10.1021/ma9601878.

21. Gaur, U., \& Wunderlich, B. (1980). The glass transition temperature of polyethylene. Macromolecules, 13(2), 445-446. https://doi.org/10.1021/ma60074a045.

22. Gilbert, D. G., \& Donald, A. M. (1986). Toughening mechanisms in high impact polystyrene. Journal of materials science, 21(5), 18191823. https://doi:10.1007/BF01114745.

23. Gilmer, T. C., \& Williams, M. (1996). Polymer mechanical properties via a new laboratory tensile tester. Journal of chemical education, 73(11), 1062. https://doi:10.1021/ed073p1062.

24. Haward, R. N., Murphy, B. M., \& White, E. F. T. (1971). Relationship between compressive yield and tensile behavior in glassy thermoplastics. Journal of Polymer Science Part A-2: Polymer Physics, 9(5), 801-814. https://doi:10.1002/pol.1971.160090503.

25. Hennig, J. (1967). Anisotropy and structure in uniaxially stretched amorphous high polymers. In Journal of Polymer Science Part C: Polymer Symposia (Vol. 16, No. 5, pp. 2751-2761). New York: Wiley Subscription Services, Inc., A Wiley Company. https://doi:10.1002/polc.5070160528.

26. Humbert, S., Lame, O., Séguéla, R., \& Vigier, G. (2011). A reexamination of the elastic modulus dependence on crystallinity in semi-crystalline polymers. Polymer, 52(21), 4899-4909. https://doi:10.1016/j.polymer.2011.07.060.

27. Instron (2020). Universal testing systems. Retrieved from https://www.instron.us/products/testing-systems/universal-testingsystems. 
28. Jia, J. H., Hu, X. Y., Wang, N., \& Tu, S. T. (2012). Test verification of an extensometer for deformation measurement of high temperature straight pipes. Measurement, 45(7), 1933-1936. https://doi:10.1016/j.measurement.2012.03.037.

29. Joyce, D. C. (1971). Survey of extrapolation processes in numerical analysis. Siam Review, 13(4), 435-490. https://doi:10.1137/1013092.

30. Kambour, R. P. (1973). A review of crazing and fracture in thermoplastics. Journal of Polymer Science: Macromolecular Reviews, 7(1), 1-154. https://doi:10.1002/pol.1973.230070101.

31. Karger-Kocsis, J. (1996). For what kind of polymer is the toughness assessment by the essential work concept straightforward? Polymer Bulletin, 37(1): 119-126. https://doi:10.1007/BF00313827.

32. Kim, H. B., Fisher, D. L., \& Fraser, B. J. (1999). Assessment and investigation of constructivist science learning environments in Korea. Research in Science \& Technological Education, 17(2), 239-249. https://doi.org/10.1080/0263514990170209.

33. Kinloch, A. J. (Ed). (2013). Fracture behaviour of polymers, (pp. 107 - 328), Springer Science \& Business Media.

34. Lee, Y. S., Lu, M. J., \& Ko, H. P. (2007). Effects of skill training on working memory capacity. Learning and Instruction, 17(3), 336-344. https://doi.org/10.1016/j.learninstruc.2007.02.010.

35. Liu, C. C., \& Chen, I. J. (2010). Evolution of constructivism. Contemporary issues in education research, 3(4), 63-66. https://doi: 10.19030/cier.v3i4.199.

36. Maths24 (2020). Calculus-Integration of functions. Retrieved from https://www.math24.net/trapezoidalrule/\#: :text=We\%20write\%20the\%20Trapezoidal\%20Rule,f(x4)\%5 D.

37. McCormick, P. D. (1975). Simple tensile testing. Journal of Chemical Education, 52(4), 242. https://doi:10.1021/ed052p242.

38. MechaniCalc (2020). Mechanical Properties of Materials. Retrieved from https://mechanicalc.com/reference/mechanical-properties-ofmaterials\#modulus-of-toughness.

39. Meyers, M. A., \& Chawla, K. K. (2008). Mechanical behavior of materials. Cambridge university press.

40. Modulus \& Matrix (2020). Plastic tensile test specimen. Retrieved from https://modulusandmatrix.co.uk/plastic-test-specimens/.

41. Mouritz, A. P. (2012). Introduction to aerospace materials. Elsevier. https://doi.org/10.1533/9780857095152.

42. Murakami, Y., \& Nemat-Nasser, S. (1983). Growth and stability of interacting surface flaws of arbitrary shape. Engineering Fracture 
Mechanics, 17(3), 193-210. https://doi:10.1016/0013-7944(83)900279.

43. Neo, M., \& Neo, T. K. (2009). Engaging students in multimediamediated Constructivist learning-Students' perceptions. Journal of Educational Technology \& Society, 12(2), 254-266.

44. NDT Resource center (2020). Toughness. Retrieved from https://www.ndeed.org/EducationResources/CommunityCollege/Materials/Mechanica 1/Toughness.htm.

45. Prabha, S. (2016). Laboratory experiences for prospective science teachers: A meta-analytic review of issues and concerns. Eur. Sci. J, 12, 235-250. https://doi: 10.19044/esj.2016.v12n34p235

46. Redifer, J. L., Bae, C. L., \& Zhao, Q. (2021). Self-efficacy and performance feedback: Impacts on cognitive load during creative thfretrinking. Learning and Instruction, 71, 101395. https://doi.org/10.1016/j.learninstruc.2020.101395.

47. Rieger, J. (1996). The glass transition temperature of polystyrene: results of a round robin test. Journal of Thermal Analysis and Calorimetry, 46(3-4), 965-972. https://doi:10.1007/bf01983614.

48. Scheirs, J., \& Priddy, D. (Eds.). (2003). Modern styrenic polymers: polystyrenes and styrenic copolymers (Vol. 6). John Wiley \& Sons.

49. Seidler, S., \& Grellmann, W. (1995). Application of the instrumented impact test to the toughness characterization of high impact thermoplastics. Polymer testing, 14(5), 453-469. https://doi:10.1016/0142-9418(95)00003-B.

50. Sjøberg, S. (2007). Constructivism and learning. International encyclopaedia of education, 3. https://doi.org/10.1016/B978-0-08044894-7.00467-X.

51. Stehling, F. C., \& Mandelkern, L. (1970). The glass temperature of linear polyethylene. Macromolecules, 3(2), 242-252. https://doi.org/10.1021/ma60014a023.

52. Talja, S., Tuominen, K., \& Savolainen, R. (2005). " Isms" in information science: Constructivism, collectivism and constructionism. Journal of documentation, 61(1), 79-101. https://doi.org/10.1108/00220410510578023.

53. Tenenbaum, G., Naidu, S., Jegede, O., \& Austin, J. (2001). Constructivist pedagogy in conventional on-campus and distance learning practice: An exploratory investigation. Learning and instruction, 11(2), 87-111. https://doi.org/10.1016/S09594752(00)00017-7. 
54. Wada, Y., \& Nakayama, A. (1971). Necking of high-density polyethylene. Journal of Applied Polymer Science, 15(1), 183-197. doi:10.1007/BF00396052.

55. Weeks, J. J. (1963). Melting temperature and change of lamellar thickness with time for bulk polyethylene. Journal of Research of the National Bureau of Standards. Section A, Physics and Chemistry, 67(5), 441. https://doi:10.6028/jres.067A.046.

56. Yang, Q., Chen, X., He, Z., Lan, F., \& Liu, H. (2016). The glass transition temperature measurements of polyethylene: determined by using molecular dynamic method. Rsc Advances, 6(15), 12053-12060. https://doi:10.1039/C5RA21115H.

57. Yeh, S. T. (2002). Using trapezoidal rule for the area under a curve calculation. Proceedings of the 27th Annual SAS ${ }^{\circledR}$ User Group International (SUGI'02). Retrieved from https://www.lexjansen.com/nesug/nesug02/ps/ps017.pdf.

58. Young, R. J., \& Lovell, P. A. (2011a). Introduction to polymers, (pp. 531-550). CRC press.

59. Young, R. J., \& Lovell, P. A. (2011b). Introduction to polymers, (pp. 583-587). CRC press.

60. Yussof, Y. M., Jamian, A. R., Roslan, S., Hamzah, Z. A. Z., \& Kabilan, M. K. (2012). Enhancing reading comprehension through cognitive and graphic strategies: A constructivism approach. Procedia-Social and Behavioral Sciences, 64, 151-160. https://doi.org/10.1016/j.sbspro.2012.11.018.

\section{Appendix}

This part of the paper describes in detail the sample geometry, individual measured results, procedures in the determination of mechanical parameters, the morphology of specimens, possible sources of errors, associated health and safety precaution, and examples of student's reports (snapshots).

\section{Samples}

Dumbbell specimens bought from Modulus and Matrix company polymers were prepared by injection molding with different colours to allow visualization of the changes in physical appearances during the deformation. The characteristics of the polymers can be found in the table below.

Table 1. Characteristics of polymers used

\begin{tabular}{|c|c|c|c|c|}
\hline Polymer & $\begin{array}{c}\text { Density } \\
\left.\mathrm{cm}^{-3}\right)\end{array}$ & $\begin{array}{c}T_{\mathrm{g}} \\
\left({ }^{\circ} \mathrm{C}\right)\end{array}$ & Colour & $\begin{array}{c}\text { Molecular weight, } \\
M_{w}(\mathrm{~kg} / \mathrm{mol}) \dagger\end{array}$ \\
\hline LDPE & 0.92 & -110 & Yellow & $>25$ \\
\hline HDPE & 0.95 & -110 & Red & $>25$ \\
\hline
\end{tabular}




\begin{tabular}{|c|c|c|c|c|}
\hline PS & 1.05 & 105 & Colourless & $>10$ \\
\hline HIPS & 1.03 & 100 & Blue & $>10$ \\
\hline
\end{tabular}

$\dagger$ data provided by the specimen manufacturer (source: Modulus and Matrix company, United Kingdom)

\section{Specimen Dimensions}

Rectangular Dumbbell specimens of each polymer were bought from Modulus and Matrix company, United Kingdom (Modulus \& Matrix. 2020). It has a thickness of about $4 \mathrm{~mm}$ and a gauge length of $\sim 80 \mathrm{~mm}$ was used. The dimensions of the specimens used can be seen below.

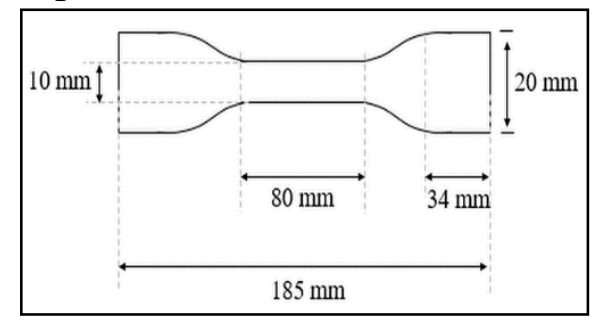

Figure 1. Dimensions of the rectangular dumbbell specimens.

\section{Tensile Test Machine}

The samples were tested by an Instron Tensile Testing Machine (Instron, 2020). The test machine comprises of a lower and upper clamp which are fixed and movable vertically by a cross-head attached. The force generated in the sample is measured via an accurately calibrated load cell positioned in the moving cross head.

\section{Test Routine and Initial Measurements}

Pre-laboratory discussions on the safety and test procedures were made before the start of the experiments. Students were allowed to interact among themselves and develop plans for the measurements. The students were then asked to relate the flexibility or the stiffness to the plastic's microstructures and their mechanical properties. One important question was whether a plastic with a greater yield strength can display greater elongation properties. Finally, they were tasked to relate the polymer's microstructure to the fracture surfaces and predict what the surface might look like before the start of the experiment.

The calibrated tensile test machine stretched the specimens with forces in $k \mathrm{~N}$ and the corresponding extensions was recorded until it failed. The force units and the associated extensions were converted, electronically, into MegaPascals (MPa) and strains (\%), respectively. To aid the conversion from $k \mathrm{~N}$ to MPa (i.e., MNm-2), the students measured the cross-sectional area $(A)$ of the specimens, as displayed in Table 2, and inserted into the computer program. A was calculated by using the average cross-sectional lengths $(L c)$ and widths $(W c)$ of three specimens $(S)$ measured individually by a digital thickness 
gauge. Table 2 shows how the areas were calculated. The stress (in MPa) was then force $(k \mathrm{~N})$ divided by $A\left(\mathrm{~m}^{2}\right)$. Strain $=\left(L_{0}-L\right) / L \times 100 \%$. Where $L$ is the original length (i.e., clamped length of $\sim 120 \mathrm{~mm}$ ) and $L_{0}$ is the new extended length.

Table 2. Cross-sectional area calculation

\begin{tabular}{|c|c|c|c|c|c|c|c|c|c|}
\hline S & $\begin{array}{c}\text { Length } \\
(l) \\
\mathrm{mm}\end{array}$ & $\begin{array}{c}\text { Length } \\
(l) \\
\mathrm{Mm}\end{array}$ & $\begin{array}{c}\text { Length } \\
(l) \\
\mathrm{mm}\end{array}$ & $\begin{array}{c}\text { Average } \\
\text { length } \\
\left(L_{\mathrm{c}}\right)\end{array}$ & $\begin{array}{c}\text { Width } \\
(\mathrm{w}) \\
\mathrm{mm}\end{array}$ & $\begin{array}{c}\text { Width } \\
(\mathrm{w}) \\
\mathrm{mm}\end{array}$ & $\begin{array}{c}\text { Width } \\
(\mathrm{w}) \\
\mathrm{mm}\end{array}$ & $\begin{array}{c}\text { Average } \\
\text { width } \\
\left(W_{\mathrm{c}}\right)\end{array}$ & $\begin{array}{c}A^{*} \\
\left(\mathrm{~mm}^{2}\right)\end{array}$ \\
\hline LDPE & 3.93 & 3.93 & 3.93 & 3.93 & 9.64 & 9.65 & 9.65 & 9.65 & 37.92 \\
\hline HDPE & 3.96 & 4.02 & 3.99 & 3.99 & 9.66 & 9.64 & 9.65 & 9.65 & 38.50 \\
\hline$P S$ & 4.09 & 4.06 & 4.08 & 4.08 & 10.32 & 10.26 & 10.28 & 10.29 & 41.94 \\
\hline$H I P S$ & 4.09 & 4.13 & 4.11 & 4.11 & 9.87 & 9.87 & 9.87 & 9.87 & 40.57 \\
\hline
\end{tabular}

\section{Apparatus Needed for the Laboratory Class}

The equipment needed for the two-hour session is;

- A universal tensile testing machine that is capable of testing materials within ranges of $0.02 \mathrm{~N}$ to $50 \mathrm{kN}$.

- A computer attached to the tensile testing machine for uploading the measurement data.

- $\quad$ Three dumbbell specimens from LDPE, HDPE, PS, and HIPS.

- A digital thickness gauge.

\section{Test Protocol}

The following protocol was followed.

(a) Measure the dimensions of each dumbbell specimen and calculate the cross-sectional area of the samples. Insert the calculated area into the machine program.

(b) Carry out tensile tests on each polymer and obtain force-extension curves. During each tensile test, observe the deformation of the specimen. Note;

i. Any change in the appearance of the material up to fracture.

ii. Whether the specimen is fractured between the clamps, at the edge or within the clamps.

iii. Whether or not the specimen formed a neck and underwent cold drawing.

(c) Convert the force-extension data into stress-strain curves in MPa and \%. Then plot a stress-strain curve in each polymer. Note: the conversion was done electronically in this work.

(d) Analyze each curve, tabulate your final results, and calculate the following:

i. Tensile modulus, $E(\mathrm{GPa})$

ii. Yield stress, $\sigma_{\mathrm{y}}(\mathrm{MPa})$

iii. Yield strain, $\varepsilon_{\mathrm{y}}(\%)$ 
iv. Ultimate stress, $\sigma_{\mathrm{u}}(\mathrm{MPa})$

v. Ultimate strain, $\varepsilon_{\mathrm{u}}(\%)$

vi. Toughness (MPa)

(e) Using concepts from the literature and lecture notes, explain the difference in the results obtained from;

i. $\quad$ LDPE and HDPE

ii. $\quad P S$ and HIPS

(f) Compare your tensile properties with those reported in the literature and describe how you may improve the accuracy of the toughness calculations.

\section{Plots of Measured Data after Ten Measurements}

The following are the individual plots from ten measurement groups. The averages of these plots were used in the main paper.

\section{LDPE}

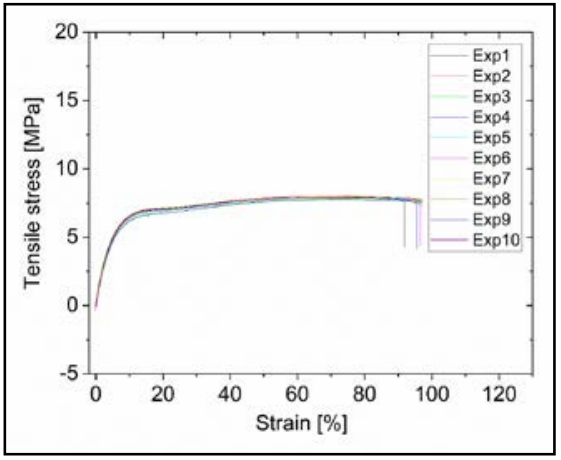

Figure 2. Plots of $L D P E$ 's stress-strain curves obtained after ten (10) experiments.

\section{HDPE}

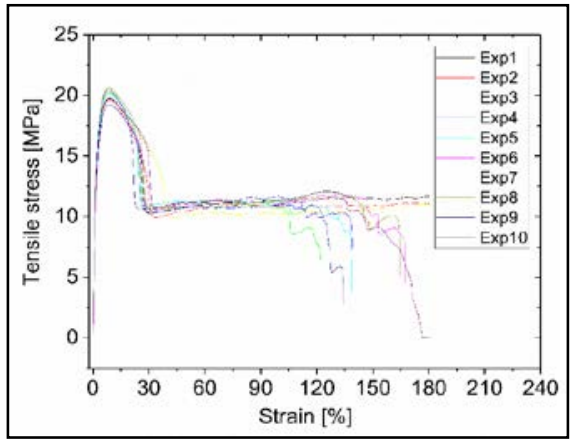

Figure 3. Plots of HDPE's stress-strain curves obtained after ten (10) experiments. 
PS

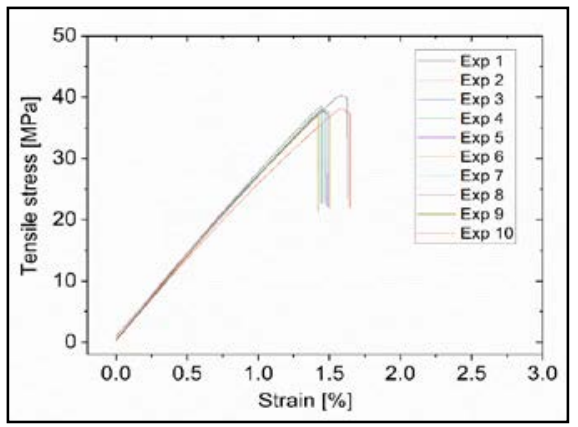

Figure 4. Plots of PS's stress-strain curves obtained after ten (10) experiments

\section{HIPS}

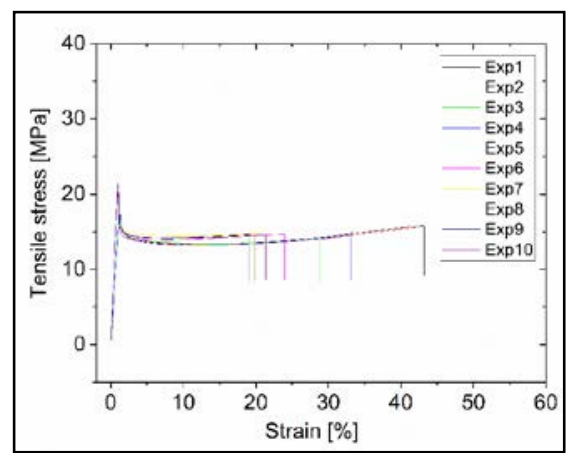

Figure 5. Plots of HIPS's stress-strain curves obtained after ten (10) experiments.

\section{Results Overview}

An average of ten (10) experimental results from ten students groups were calculated and plotted as shown in Figure 6. From the graph, the PS looked very rigid and breaks at stress close to the yield point, while the HIPS yielded and elongated to an appreciable length. There was a clear distinction between the LDPE and HDPE even though both plastics elongated before breaking. There was a pronounced yielding for the HDPE than the LDPE.

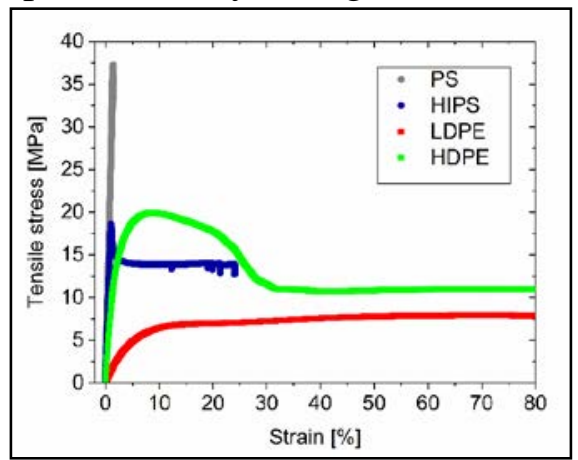

Figure 6. Overview of results from all specimens tested. This is an average plot from each plastic material after ten (10) experimental measurements were selected from measured experimental results. See individual plots above. 


\section{Determination of Elastic Modulus (E)}

Using equation (1) and the same procedure described within the main paper, the following $E$ values were calculated.

\section{HDPE}

From Figure 7,

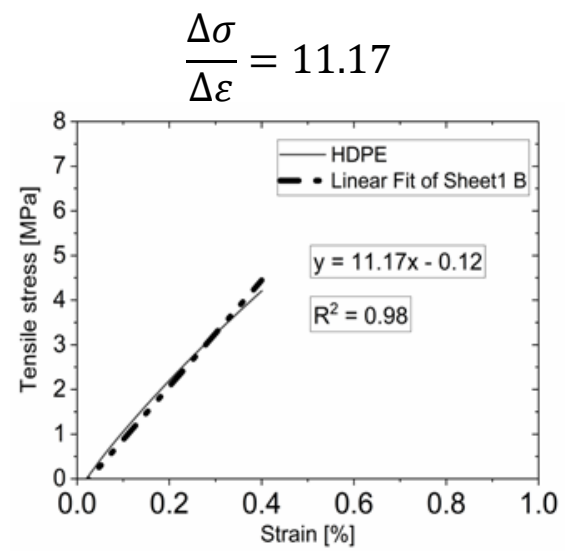

Figure 7. HDPE slope determination at the linear region. The average stress-strain curve from the ten experimental measurements was used.

Hence,

$$
\begin{gathered}
E(P a)=11.17 \times 100(M P a) \\
E(P a)=1117(M P a) \\
E(P a)=1.12(G P a)
\end{gathered}
$$

Therefore, the $E$ value for $H D P E$ was $1.12 \mathrm{GPa}$.

PS

From Figure 8,

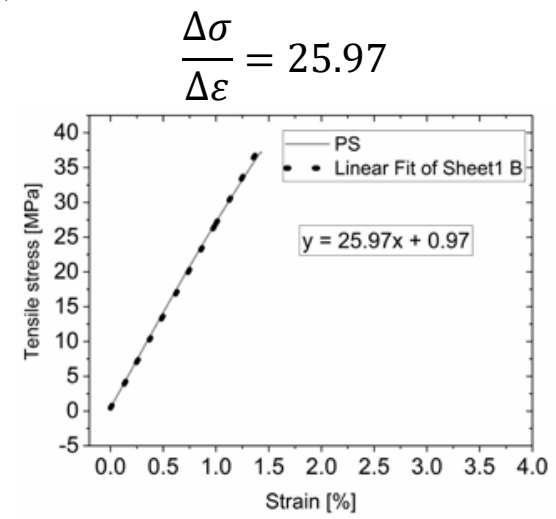

Figure 8. $P S$ slope determination at the linear region. The average stress-strain curve from the ten experimental measurements was used 
Hence,

$$
\begin{gathered}
E(P a)=25.97 \times 100(M P a) \\
E(P a)=2597(M P a) \\
E(P a)=2.6(G P a)
\end{gathered}
$$

Therefore, the $E$ value for $P S$ was $2.60 \mathrm{GPa}$.

\section{HIPS}

From Figure 9,

$$
\frac{\Delta \sigma}{\Delta \varepsilon}=18.88
$$

Hence,

$$
\begin{gathered}
E=18.88 \times 100(M P a) \\
E=1888(M P a) \\
E=1.9(G P a)
\end{gathered}
$$

Therefore, the $E$ value for HIPS was $1.90 \mathrm{GPa}$.

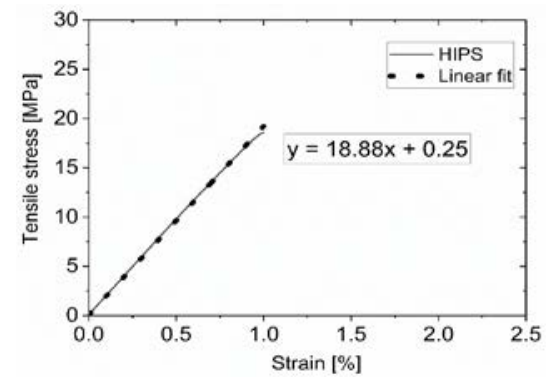

Figure 9. HIPS slope determination at the linear region. The average stress-strain curve from the ten experimental measurements was used.

\section{Determination of Toughness}

Similar to the procedures within the main paper, the Trapezium rule was used as follows;

$$
\text { Area }=\frac{\Delta x}{2}\left[y_{1}+y_{n}+2\left(y_{2}+y_{3}+y_{4}+\ldots \ldots y_{n}\right)\right]
$$

\section{HDPE}

In Figure 10 below, the toughness of HDPE plastic was estimated using $\Delta x=0.072$ because $n$ was selected to be 25 while $a=0$ and $b=1.8$ (i.e., value as decimal). 


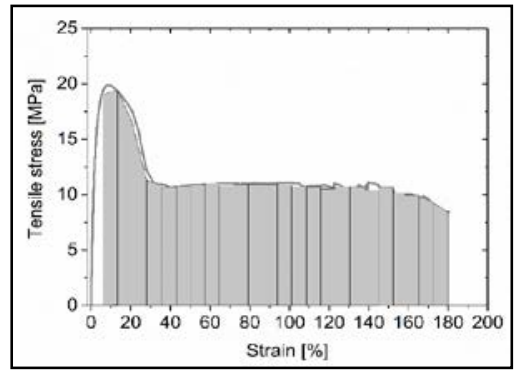

Figure 10. Determination of toughness under the HPDE tensile curve

Starting from 0 and a $\Delta x$ of $0.072, x$ values were generated and the corresponding $y$ values of $x$ were picked from the curve in Figure 10 (see Table 3 below). In Table 3, the required coefficients were multiplied and the resulting values were summed as in the Trapezium formula (i.e., summation of $\left.y_{1}, 2 y_{2}, 2 y_{3}, \ldots \ldots . . y_{n}\right)$.

Table 3. Estimation of HDPE toughness

\begin{tabular}{|l|l|l|l|}
\hline$x$ & $Y$ & Coefficient $(c)$ & Product $=c \times y$ \\
\hline 0 & 0 & 1 & 0 \\
\hline 0.072 & 19.75 & 2 & 39.5 \\
\hline 0.144 & 19.14 & 2 & 38.28 \\
\hline 0.216 & 16.89 & 2 & 33.78 \\
\hline 0.288 & 12.04 & 2 & 24.08 \\
\hline 0.36 & 10.92 & 2 & 21.84 \\
\hline 0.432 & 10.71 & 2 & 21.42 \\
\hline 0.504 & 10.86 & 2 & 21.72 \\
\hline 0.576 & 10.93 & 2 & 21.86 \\
\hline 0.648 & 10.98 & 2 & 21.96 \\
\hline 0.72 & 10.98 & 2 & 21.96 \\
\hline 0.792 & 11.00 & 2 & 22.00 \\
\hline 0.864 & 11.00 & 2 & 22.00 \\
\hline 0.936 & 11.03 & 2 & 22.06 \\
\hline 1.008 & 11.03 & 2 & 22.06 \\
\hline 1.08 & 10.73 & 2 & 21.46 \\
\hline 1.152 & 10.78 & 2 & 21.56 \\
\hline 1.224 & 10.57 & 2 & 21.14 \\
\hline 1.296 & 10.44 & 2 & 20.88 \\
\hline 1.368 & 10.78 & 2 & 21.56 \\
\hline 1.44 & 10.96 & 2 & 21.92 \\
\hline 1.512 & 10.2 & 2 & 20.40 \\
\hline 1.584 & 10.05 & 2 & 20.10 \\
\hline 1.656 & 9.07 & 2 & 18.14 \\
\hline 1.728 & 9.16 & 2 & 18.32 \\
\hline 1.8 & 8.43 & 1 & 8.43 \\
\hline & & Sum & $\mathbf{5 6 8 . 4 3}$ \\
\hline & & & \\
\hline & & 2 & \\
\hline
\end{tabular}

The area is then given by; 


$$
\begin{gathered}
\text { Area }=\frac{0.072}{2}[568.43] \\
\text { Area }=20.5 \mathrm{MPa}
\end{gathered}
$$

Hence, the toughness of HDPE was 20.5 MPa.

PS

In Figure 11 below, the toughness of $P S$ plastic was estimated using $\Delta x=0.00149$ because $n$ was selected to be 10 while $a=0$ and $b=0.0149$ (i.e., value as decimal).

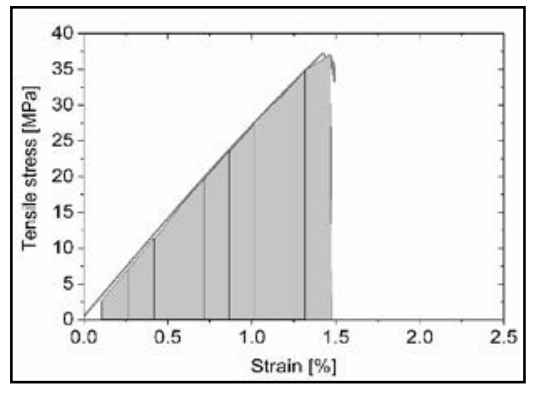

Figure 11. Determination of toughness under the $P S$ tensile curve

Starting from 0 and a $\Delta x$ of $0.00149, x$ values were generated and the corresponding $y$ values of $x$ were picked from the curve in Figure 11 (see Table 4 below). The procedure above was followed.

Table 4. Estimation of PS toughness

\begin{tabular}{|l|l|l|l|}
\hline$X$ & $Y$ & Coefficient $(c)$ & Product $=c \times y$ \\
\hline 0 & 0 & 1 & 0 \\
\hline 0.00149 & 4.55 & 2 & 9.10 \\
\hline 0.00298 & 8.56 & 2 & 17.12 \\
\hline 0.00447 & 12.7 & 2 & 25.40 \\
\hline 0.00596 & 16.71 & 2 & 33.42 \\
\hline 0.00745 & 20.63 & 2 & 41.26 \\
\hline 0.00894 & 24.45 & 2 & 48.90 \\
\hline 0.01043 & 28.21 & 2 & 56.42 \\
\hline 0.01192 & 31.81 & 2 & 63.62 \\
\hline 0.01341 & 35.4 & 2 & 70.80 \\
\hline 0.0149 & 35.95 & 1 & 35.95 \\
\hline & & Sum & $\mathbf{4 0 1 . 9 9}$ \\
\hline
\end{tabular}

The area is then given by;

$$
\begin{gathered}
\text { Area }=\frac{0.00149}{2} \text { [401.99] } \\
\text { Area }=0.3 \mathrm{MPa}
\end{gathered}
$$

Hence, the toughness of PS was 0.3 MPa. 


\section{HIPS}

In Figure 12 below, the toughness of HIPS plastic was estimated using $\Delta x=0.012$ because $n$ was selected to be 20 while $a=0$ and $b=0.24$ (i.e., value as decimal).

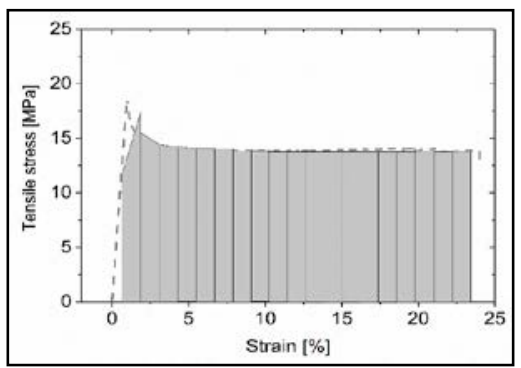

Figure 12. Determination of toughness under the HIPS tensile curve

Starting from 0 and a $\Delta x$ of $0.012, x$ values were generated and the corresponding $y$ values of $x$ were picked from the curve in Figure 12 (see Table 5 below). The previous procedure was followed.

Table 5. Estimation of HIPS toughness

\begin{tabular}{|l|l|l|l|}
\hline$X$ & $y$ & Coefficient $(c)$ & Product $=c \times y$ \\
\hline 0 & 0 & 1 & 0 \\
\hline 0.012 & 18.45 & 2 & 36.90 \\
\hline 0.024 & 14.50 & 2 & 29.00 \\
\hline 0.036 & 14.18 & 2 & 28.36 \\
\hline 0.048 & 14.02 & 2 & 28.04 \\
\hline 0.060 & 13.95 & 2 & 27.90 \\
\hline 0.072 & 13.90 & 2 & 27.80 \\
\hline 0.084 & 13.88 & 2 & 27.76 \\
\hline 0.096 & 13.88 & 2 & 27.76 \\
\hline 0.108 & 13.88 & 2 & 27.76 \\
\hline 0.120 & 13.88 & 2 & 27.76 \\
\hline 0.132 & 13.88 & 2 & 27.76 \\
\hline 0.144 & 13.90 & 2 & 27.80 \\
\hline 0.156 & 13.94 & 2 & 27.88 \\
\hline 0.168 & 13.98 & 2 & 27.96 \\
\hline 0.180 & 14.04 & 2 & 28.08 \\
\hline 0.192 & 13.98 & 2 & 27.96 \\
\hline 0.204 & 13.98 & 2 & 27.96 \\
\hline 0.216 & 13.80 & 2 & 27.60 \\
\hline 0.228 & 13.80 & 2 & 27.60 \\
\hline 0.240 & 13.59 & 1 & 13.59 \\
\hline & & Sum & 553.23 \\
\hline & & &
\end{tabular}

The area is then given by;

$$
\begin{gathered}
\text { Area }=\frac{0.012}{2}[553.23] \\
\text { Area }=3.3 \mathrm{MPa}
\end{gathered}
$$


Hence, the toughness of HIPS was 3.3 MPa.

\section{Specimen Morphological Details}

The following images show details of the specimens captured by the students during and after the tensile deformation.

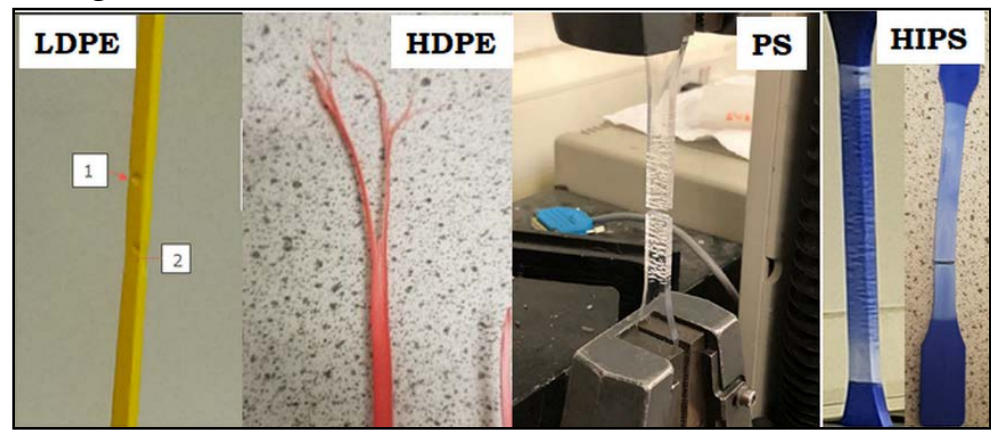

Figure 13. Details of the specimens during and after the tensile test. The LDPE had two visible surface voids during the plastic deformation. The ends of the HDPE transformed into

fibrous structures after the fracture. The PS developed perpendicular crack zones (i.e., crazing zones) during the fracture and the HIPS had crazing zones plus large deformations before cracking.

\section{Possible Sources of Errors}

It is worthy to mention that the specimen's cross-sectional areas and their measured stress-strain curves must not be averaged if the focus is on result accuracy. Moreover, there may be several sources of errors that must be considered. Fluctuations in the individual graphs may be due to internal crazing or necking at the grip section of the test specimen. Unintended surface flaws (Murakami \& Nemat-Nasser, 1983), as a result of manufacturing or specimen handling faults, may results to initial cracks and might lower the expected mechanical properties. Human errors might occur during the reading of values from the stress-strain curves. There might also be instrumental errors during the calculation of the specimen's cross-sectional area due to possible errors from the digital thickness gauge. Furthermore, errors might also occur during the conversion of units and, most importantly, during the extension conversion to strain values. In those cases, the use of an extensometer (Jia et al., 2012) is recommended for data accuracy.

\section{Hazard and Safety Precautions}

The following health and safety precautions must be followed:

- Safety glasses and lab coats MUST be worn at all times in the laboratory.

- Students must stand, at least, two (2) meters away from the tensile testing machine during measurements. 
- Eating, drinking, and smoking are NOT PERMITTED in the laboratory.

- Walkways between benches should be kept clean and free from obstruction.

\section{Samples of Student's Reports}

Anonymous snapshots of selected student's reports.

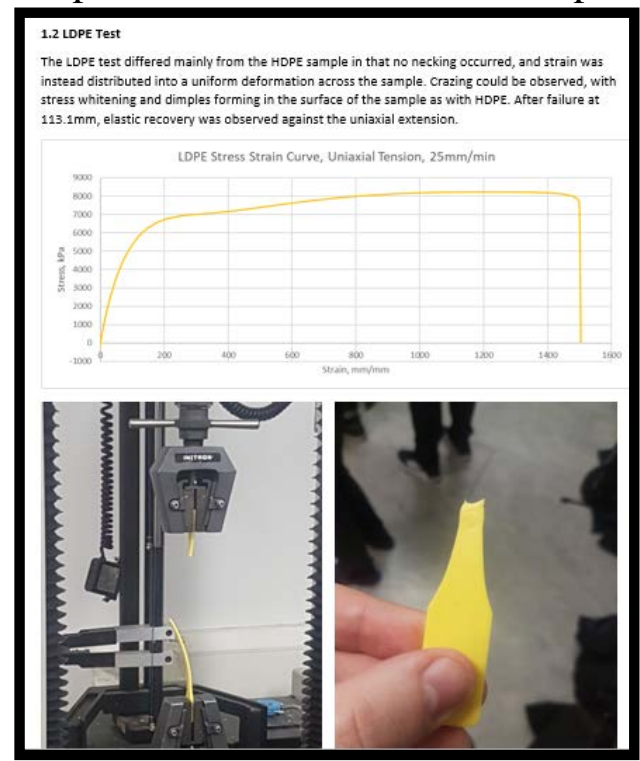

Student 1

- LDPE:

- $E=(140-1860) \times 10^{6} \mathrm{~N} \mathrm{~m}^{-2}$

- $\sigma_{y}=(0.2-11.9) \times 10^{6} \mathrm{~N} \mathrm{~m}^{-2} \quad$ [1]

- $\varepsilon_{y}=19 \%$ (3)

- $\sigma_{u}=(5-26) \times 10^{6} \mathrm{~N} \mathrm{~m}^{-2}$

- $\varepsilon_{u}=(20-40) \%$ [1]

- Toughness $=6.06 \times 10^{6} \mathrm{~N} \mathrm{~m}^{-2}$ [5]

The experimental value of Young's Modulus is lower than its theoretical value. The yield and ultimate stresses are within their respective range of theoretical values. The experimental yield strain has a value that is close to its theoretical value. The experimental Ultimate Strain is much larger than its theoretical predictions, this discrepancy in value might be due to the experimental value experiencing more plastic deformation before fracture than what was written down in theory. The experimental toughness is also much larger than what is written down in the research journal, despite their

\section{Student 1}




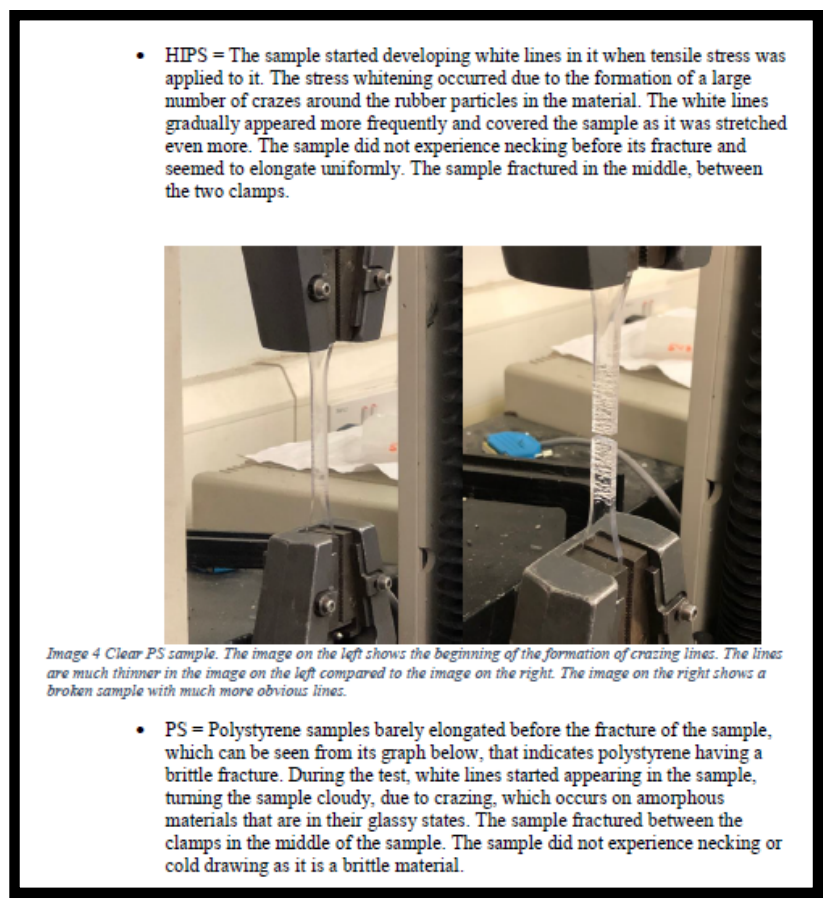

Student 2

\section{Compare of experimental values and literature.}

Values from literature

\begin{tabular}{|c|c|c|c|c|c|}
\hline & $\begin{array}{l}\text { yield } \\
\text { stress(MPa) }\end{array}$ & yield strain & $\begin{array}{l}\text { ultimate } \\
\text { stress(MPa) }\end{array}$ & $\begin{array}{l}\text { ultimate } \\
\text { strain }\end{array}$ & $\begin{array}{l}\text { Young's } \\
\text { modulus(Gpa) }\end{array}$ \\
\hline HDPE & $15.2-42.1$ & $6.00-13.0 \%$ & $11.7-44.0$ & $7.00-2000 \%$ & $0.650-2.07$ \\
\hline LDPE & $8.48-26.2$ & $11.0-640 \%$ & $10.3-18.0$ & $100-850 \%$ & $0.190-0.520$ \\
\hline PS & $34.0-55.0$ & $1.00-35.0 \%$ & $35.0-59.0$ & $1.00-35.0 \%$ & $2.25-4.71$ \\
\hline HIPS & $20-28$ & $1.20 \%$ & 32 & $10-55 \%$ & $1.8-2.28$ \\
\hline
\end{tabular}

The materials have different properties with different thermal and deform histories. The type and histories of specimen can not be known, so that the value from literature can not be same as the value got from experiment. The young's modulus of specimen are not in the range of the value from literature. HIPS specimen perform very different with data from literature, this might because the type of HIPS in literature is not the same as specimen. The others are all in the range of data from literature.

\section{Student 2}


5. Compare of experimental values and literature.

Values from literature

$$
\begin{array}{llclll} 
& \begin{array}{l}
\text { yield } \\
\text { stress(MPa) }
\end{array} & \text { yield strain } & \begin{array}{l}
\text { ultimate } \\
\text { stress(MPa) }
\end{array} & \begin{array}{l}
\text { ultimate } \\
\text { strain }
\end{array} & \begin{array}{l}
\text { Young's } \\
\text { modulus(Gpa) }
\end{array} \\
\text { HDPE } & 15.2-42.1 & 6.00-13.0 \% & 11.7-44.0 & 7.00-2000 \% & 0.650-2.07 \\
\text { LDPE } & 8.48-26.2 & 11.0-640 \% & 10.3-18.0 & 100-850 \% & 0.190-0.520 \\
\text { PS } & 34.0-55.0 & 1.00-35.0 \% & 35.0-59.0 & 1.00-35.0 \% & 2.25-4.71 \\
\text { HIPS } & 20-28 & 1.20 \% & 32 & 10-55 \% & 1.8-2.28
\end{array}
$$

The materials have different properties with different thermal and deform histories. The type and histories of specimen can not be known, so that the value from literature can not be same as the value got from experiment. The young's modulus of specimen are not in the range of the value from literature. HIPS specimen perform very different with data from literature, this might because the type of HIPS in literature is not the same as specimen. The others are all in the range of data from literature.

\section{Difference explaining}

PS and HDPE: The elongation of HDPE can be 5 times its original length and PS has very small elongation, this is because HDPE is above its $T_{5}$ and PS is below its $T_{5}$ which means HDPE is more viscoelastic than PS so that HDPE is rubber-like at room T and PS is glassy. The plot of PS shows brittle behavior and have Young's modulus higher than HDPE, but toughness is much smaller than that of HDPE. The reason of that is HDPE absorb more energy before broken, due to its large range of plastic deformation.

PS and HIPS: The elongation of HIPS is significant larger than PS, this is because rubber particles in HIPS can increasing $G_{c}$ without reducing too much modulus of polymer so that HIPS can absorb much more energy than PS before broken. Rubber particles can initiate local plastic deformation around them which give more plastic zones in crack region rather than few plastic zones in PS. High level of crazing are controlled in HIPS.

\section{Student 3}

